\title{
COMPLEMENTARY DISTANCE SPECTRA AND COMPLEMENTARY DISTANCE ENERGY OF LINE GRAPHS OF REGULAR GRAPHS
}

\author{
H. S. RAMAne ${ }^{1}$ AND K. C. NANDEesh ${ }^{2}$ \\ ${ }^{1}$ Department of Mathematics, Karnatak University, \\ Dharwad - 580003, India \\ e-mail: hsramane@yahoo.com \\ ${ }^{2}$ Department of Mathematics, Karnatak University, \\ Dharwad - 580003, India \\ e-mail: nandeeshkc@yahoo.com
}

\begin{abstract}
The complementary distance (CD) matrix of a graph $G$ is defined as $C D(G)=\left[c_{i j}\right]$, where $c_{i j}=1+D-d_{i j}$ if $i \neq j$ and $c_{i j}=0$, otherwise, where $D$ is the diameter of $G$ and $d_{i j}$ is the distance between the vertices $v_{i}$ and $v_{j}$ in $G$. The $C D$-energy of $G$ is defined as the sum of the absolute values of the eigenvalues of $C D$-matrix. Two graphs are said to be $C D$-equienergetic if they have same $C D$-energy. In this paper we show that the complement of the line graph of certain regular graphs has exactly one positive $C D$-eigenvalue. Further we obtain the $C D$-energy of line graphs of certain regular graphs and thus constructs pairs of $C D$-equienergetic graphs of same order and having different $C D$-eigenvalues.
\end{abstract}

Key words and Phrases: Complementary distance eigenvalues, adjacency eigenvalues, line graphs, complementary distance energy.

\begin{abstract}
Abstrak. Matriks complementary distance (CD) dari sebuah graph $G$ didefinisikan sebagai $C D(G)=\left[c_{i j}\right]$, dimana $c_{i j}=1+D-d_{i j}$ jika $i \neq j$ dan $c_{i j}=0$, atau yang lain, dimana $D$ adalah diameter $G$ dan $d_{i j}$ adalah jarak antara titik-titik $v_{i}$ dan $v_{j}$ di $G$. Energi- $C D$ dari $G$ didefinisikan sebagai jumlahan dari nilai mutlak nilai-nilai eigen matriks- $C D$. Dua graf disebut ekuienergetik- $C D$ jika mereka mempunyai energi- $C D$ yang sama. Dalam paper ini kami menunjukkan komplemen graf garis dari graf-graf regular tertentu mempunyai tepat satu nilai eigen- $C D$ positif. Lebih jauh, kami mendapatkan energi- $C D$ graf garis dari graf-graf regular tertentu dan selanjutnya mengkonstruksi pasangan graf-graf ekuienergetik- $C D$-equienergetic berorde sama dan mempunyai nilai-nilai eigen- $C D$ berbeda.
\end{abstract}

2000 Mathematics Subject Classification: 05C50, 05C12.

Received: 20-05-2015, revised: 17-02-2016, accepted: 19-02-2016. 
Kata kunci: Nilai-nilai eigen complementary distance, Nilai-nilai eigen ketetanggaan, graf-graf garis, energi complementary distance.

\section{INTRODUCTION}

Let $G$ be a simple, undirected, connected graph with $n$ vertices and $m$ edges. Let the vertex set of $G$ be $V(G)=\left\{v_{1}, v_{2}, \ldots, v_{n}\right\}$. The adjacency matrix of a graph $G$ is the square matrix $A=A(G)=\left[a_{i j}\right]$, in which $a_{i j}=1$ if $v_{i}$ is adjacent to $v_{j}$ and $a_{i j}=0$, otherwise. The eigenvalues of $A(G)$ are the adjacency eigenvalues of $G$, and they are labeled as $\lambda_{1} \geq \lambda_{2} \geq \cdots \geq \lambda_{n}$. These form the adjacency spectrum of $G[4]$.

The distance between the vertices $v_{i}$ and $v_{j}$, denoted by $d_{i j}$, is the length of the shortest path joining $v_{i}$ and $v_{j}$. The diameter of a graph $G$, denoted by $\operatorname{diam}(G)$, is the maximum distance between any pair of vertices of $G$ [3]. A graph $G$ is said to be $r$-regular graph if all of its vertices have same degree equal to $r$.

The complementary distance between the vertices $v_{i}$ and $v_{j}$, denoted by $c_{i j}$ is defined as $c_{i j}=1+D-d_{i j}$, where $D$ is the diameter of $G$ and $d_{i j}$ is the distance between $v_{i}$ and $v_{j}$ in $G$.

The complementary distance matrix or $C D$-matrix [7] of a graph $G$ is an $n \times n$ matrix $C D(G)=\left[c_{i j}\right]$, where

$$
c_{i j}=\left\{\begin{array}{ccc}
1+D-d_{i j}, & \text { if } & i \neq j \\
0, & \text { if } & i=j .
\end{array}\right.
$$

The complementary distance matrix is an important source of structural descriptors in the quantitative structure property relationship (QSPR) model in chemistry $[7,8]$.

The eigenvalues of $C D(G)$ labeled as $\mu_{1} \geq \mu_{2} \geq \cdots \geq \mu_{n}$ are said to be the complementary distance eigenvalues or $C D$-eigenvalues of $G$ and their collection is called $C D$-spectra of $G$. Two non-isomorphic graphs are said to be $C D$-cospectral if they have same $C D$-spectra.

The complementary distance energy or $C D$-energy of a graph $G$ denoted by $C D E(G)$ is defined as

$$
C D E(G)=\sum_{i=1}^{n}\left|\mu_{i}\right| .
$$


The Eq. (1) is defined in full analogy with the ordinary graph energy $E(G)$, defined as [5]

$$
E(G)=\sum_{i=1}^{n}\left|\lambda_{i}\right|
$$

Two graphs $G_{1}$ and $G_{2}$ are said to be equienergetic if $E\left(G_{1}\right)=E\left(G_{2}\right)$. Results on non cospectral equienergetic graphs can be found in $[1,2,12,13,17]$. For more details about ordinary graph energy one can refer [9].

Two connected graphs $G_{1}$ and $G_{2}$ are said to be complementary distance equienergetic or $C D$-equienergetic if $C D E\left(G_{1}\right)=C D E\left(G_{2}\right)$. Trivially, the $C D$ cospectral graphs are $C D$-equienergetic. In this paper we obtain the $C D$-energy of line graphs of certain regular graphs and thus construct $C D$-equienergetic graphs having different $C D$-spectra.

We need following results.

Theorem 1.1. [4] If $G$ is an $r$-regular graph, then its maximum adjacency eigenvalue is equal to $r$.

The line graph of $G$, denoted by $L(G)$ is the graph whose vertices corresponds to the edges of $G$ and two vertices of $L(G)$ are adjacent if and only if the corresponding edges are adjacent in $G$ [6]. If $G$ is a regular graph of order $n$ and of degree $r$ then the line graph $L(G)$ is a regular graph of order $n r / 2$ and of degree $2 r-2$.

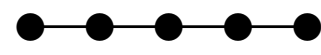

$F_{1}$

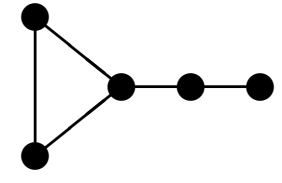

$F_{2}$

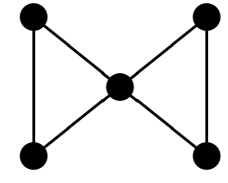

$F_{3}$

Figure 1: The forbidden induced subgraphs

Theorem 1.2. [10, 11] For a connected graph $G$, diam $(L(G)) \leq 2$ if and only if none of the three graphs $F_{1}, F_{2}$ and $F_{3}$ of Fig. 1 is an induced subgraph of $G$.

Theorem 1.3. [15] If $\lambda_{1}, \lambda_{2}, \ldots, \lambda_{n}$ are the adjacency eigenvalues of a regular graph $G$ of order $n$ and of degree $r$, then the adjacency eigenvalues of $L(G)$ are

$$
\begin{aligned}
\lambda_{i}+r-2, & i=1,2, \ldots, n, \quad \text { and } \\
-2, & n(r-2) / 2 \text { times. }
\end{aligned}
$$

Theorem 1.4. [14] Let $G$ be an $r$-regular graph of order $n$. If $r, \lambda_{2}, \ldots, \lambda_{n}$ are the adjacency eigenvalues of $G$, then the adjacency eigenvalues of $\bar{G}$, the complement of $G$, are $n-r-1$ and $-\lambda_{i}-1, i=2,3, \ldots, n$. 
Lemma 1.5. [16] If for any two adjacent vertices $u$ and $v$ of a graph $G$, there exists a third vertex $w$ which is not adjacent to either $u$ or $v$, then

(i) $\bar{G}$ is connected and

(ii) $\operatorname{diam}(\bar{G})=2$.

\section{2. $C D$-EIGENVALUES}

Theorem 2.1. Let $G$ be an $r$-regular graph on $n$ vertices and $\operatorname{diam}(G)=2$. If $r, \lambda_{2}, \ldots, \lambda_{n}$ are the adjacency eigenvalues of $G$, then $C D$-eigenvalues of $G$ are $n+r-1$ and $\lambda_{i}-1, i=2,3, \ldots, n$.

Proof. Since $G$ is an $r$-regular graph, $\mathbf{1}=[1,1, \ldots, 1]^{\prime}$ is an eigenvector of $A=A(G)$ corresponding to the eigenvalue $r$. Set $\mathbf{z}=\frac{1}{\sqrt{n}} \mathbf{1}$ and let $P$ be an orthogonal matrix with its first column equal to $\mathbf{z}$ such that $P^{\prime} A P=\operatorname{diag}\left(r, \lambda_{2}, \ldots, \lambda_{n}\right)$. Since $\operatorname{diam}(G)=2$, the $C D$-matrix $C D(G)$ can be written as $C D(G)=J+A-I$, where $J$ is the matrix whose all entries are equal to 1 and $I$ is an identity matrix. Therefore

$$
\begin{aligned}
P^{\prime}(C D) P & =P^{\prime}(J+A-I) P \\
& =P^{\prime} J P+P^{\prime} A P-I \\
& =\operatorname{diag}\left(n+r-1, \lambda_{2}-1, \ldots, \lambda_{n}-1\right),
\end{aligned}
$$

where we have used the fact that any column of $P$ other than the first column is orthogonal to the first column. Hence the eigenvalues of $C D(G)$ are $n+r-1$ and $\lambda_{i}-1, i=2,3, \ldots, n$.

Theorem 2.2. Let $G$ be an r-regular graph of order $n$. Let $L(G)$ be the line graph of $G$ such that for any two adjacent vertices $u$ and $v$ of $L(G)$, there exists a third vertex $w$ in $L(G)$ which is not adjacent to either $u$ or $v$. Then $\overline{L(G)}$, the complement of $L(G)$, has exactly one positive $C D$-eigenvalue, equal to $r(n-2)$.

Proof. Let the adjacency eigenvalues of $G$ be $r, \lambda_{2}, \ldots, \lambda_{n}$. From Theorem 1.3 , the adjacency eigenvalues of $L(G)$ are

$$
\left.\begin{array}{rl}
2 r-2, & \text { and } \\
\lambda_{i}+r-2, & i=2,3, \ldots, n, \quad \text { and } \\
-2, & n(r-2) / 2 \text { times. }
\end{array}\right\}
$$

From Theorem 1.4 and the Eq. (3), the adjacency eigenvalues of $\overline{L(G)}$ are

$$
\left.\begin{array}{rl}
(n r / 2)-2 r+1, & \text { and } \\
-\lambda_{i}-r+1, & i=2,3, \ldots, n, \quad \text { and } \\
1, & n(r-2) / 2 \text { times. }
\end{array}\right\}
$$


The graph $\overline{L(G)}$ is a regular graph of order $n r / 2$ and of degree $(n r / 2)-2 r+1$. Since for any two adjacent vertice $u$ and $v$ of $L(G)$ there exists a third vertex $w$ which is not adjacent to either $u$ or $v$ in $L(G)$, by Lemma 1.5 , $\operatorname{diam}(\overline{L(G)})=2$. Therefore by Theorem 2.1 and Eq. (4), the $C D$-eigenvalues of $\overline{L(G)}$ are

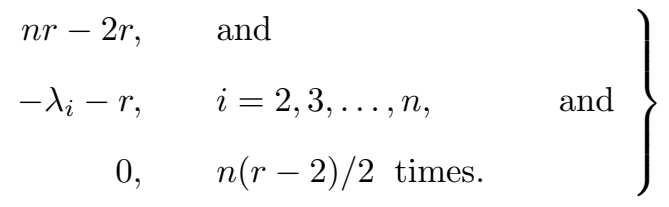

All adjacency eigenvalues of a regular graph of degree $r$ satisfy the condition $-r \leq \lambda_{i} \leq r$ [4]. Therefore $\lambda_{i}+r \geq 0, i=1,2, \ldots, n$. The theorem follows from Eq. (5).

\section{3. $C D$-ENERGY}

Theorem 3.1. Let $G$ be an $r$-regular graph of order $n$. Let $L(G)$ be the line graph of $G$ such that for any two adjacent vertices $u$ and $v$ of $L(G)$, there exists a third vertex $w$ in $L(G)$ which is not adjacent to either $u$ or $v$. Then $C D E(\overline{L(G)})=2 r(n-2)$.

Proof. Bearing in mind Theorem 2.2 and Eq. (5), the $C D$-energy of $\overline{L(G)}$ is computed as:

$$
\begin{aligned}
C D E(\overline{L(G)}) & =n r-2 r+\sum_{i=2}^{n}\left(\lambda_{i}+r\right)+|0| \times \frac{n(r-2)}{2} \\
& =2 r(n-2) \quad \text { since } \quad \sum_{i=2}^{n} \lambda_{i}=-r .
\end{aligned}
$$

Theorem 3.2. Let $G$ be a connected, $r$-regular graph with $n>3$ vertices and let none of the three graphs $F_{1}, F_{2}$ and $F_{3}$ of Fig. 1 is an induced subgraph of $G$.

(i) If the smallest adjacency eigenvalue of $G$ is greater than or equal to $3-r$, then $C D E(L(G))=3 n(r-2)$.

(ii) If the second largest adjacency eigenvalue of $G$ is smaller than $3-r$, then $C D E(L(G))=n r+4 r-6$.

Proof. Let $r, \lambda_{2}, \lambda_{3}, \ldots, \lambda_{n}$ be the adjacency eigenvalues of a regular graph $G$. Then from Theorem 1.3, the adjacency eigenvalues of $L(G)$ are

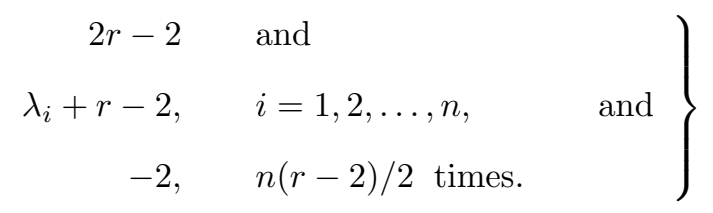


The graph $G$ is regular of degree $r$ and has order $n$. Therefore $L(G)$ is a regular graph on $n r / 2$ vertices and of degree $2 r-2$. As none of the three graphs $F_{1}, F_{2}$ and $F_{3}$ of Fig. 1 is an induced subgraph of $G$, from Theorem 1.2, $\operatorname{diam}(L(G))=2$. Therefore from Theorem 2.1 and Eq. (6), the $C D$-eigenvalues of $L(G)$ are

$$
\left.\begin{array}{rll}
(n r+4 r-6) / 2, & \text { and } & \\
\lambda_{i}+r-3, & i=2,3, \ldots, n & \\
-3, & n(r-2) / 2 \text { times. } & \text { and }
\end{array}\right\}
$$

Therefore

$$
C D E(L(G))=\left|\frac{n r+4 r-6}{2}\right|+\sum_{i=2}^{n}\left|\lambda_{i}+r-3\right|+|-3| \frac{n(r-2)}{2} .
$$

(i) By assumption, $\lambda_{i}+r-3 \geq 0, i=2,3, \ldots n$, then from Eq. (8)

$$
\begin{aligned}
C D E(L(G)) & =\frac{n r+4 r-6}{2}+\sum_{i=2}^{n}\left(\lambda_{i}+r-3\right)+\frac{3 n(r-2)}{2} \\
& =\frac{n r+4 r-6}{2}+\sum_{i=2}^{n} \lambda_{i}+(n-1)(r-3)+\frac{3 n(r-2)}{2} \\
& =3 n(r-2) \quad \text { since } \quad \sum_{i=2}^{n} \lambda_{i}=-r .
\end{aligned}
$$

(ii) By assumption, $\lambda_{i}+r-3<0, i=2,3, \ldots n$, then from Eq. (8)

$$
\begin{aligned}
C D E(L(G)) & =\frac{n r+4 r-6}{2}-\sum_{i=2}^{n}\left(\lambda_{i}+r-3\right)+\frac{3 n(r-2)}{2} \\
& =\frac{n r+4 r-6}{2}-\sum_{i=2}^{n} \lambda_{i}-(n-1)(r-3)+\frac{3 n(r-2)}{2} \\
& =n r+4 r-6 \quad \text { since } \quad \sum_{i=2}^{n} \lambda_{i}=-r .
\end{aligned}
$$

Corollary 3.3. Let $G$ be a connected, cubic graph with $n$ vertices and let none of the three graphs $F_{1}, F_{2}$ and $F_{3}$ of Fig. 1 is an induced subgraph of $G$. Then $C D E(L(G))=3 n+E(G)$.

Proof. Substituting $r=3$ in Eq. (8) we get 


$$
\begin{aligned}
C D(L(G)) & =\left|\frac{3 n+6}{2}\right|+\sum_{i=2}^{n}\left|\lambda_{i}\right|+|-3| \frac{n}{2} \\
& =\frac{3 n+6}{2}+(E(G)-3)+\frac{3 n}{2} \\
& =3 n+E(G) .
\end{aligned}
$$

\section{4. $C D$-EQUiENERGETIC GRAPHS}

Lemma 4.1. Let $G_{1}$ and $G_{2}$ be regular graphs of the same order and of the same degree. Then following holds:

(i) $L\left(G_{1}\right)$ and $L\left(G_{2}\right)$ are of the same order, same degree and have the same number of edges.

(ii) $\overline{L\left(G_{1}\right)}$ and $\overline{L\left(G_{2}\right)}$ are of the same order, same degree and have the same number of edges.

Proof. Statement (i) follows from the fact that the line graph of a regular graph is a regular and that the number of edges of $G$ is equal to the number of vertices of $L(G)$. Statement (ii) follows from the fact that the complement of a regular graph is a regular and that the number of vertices of a graph and its complement is equal.

Lemma 4.2. Let $G_{1}$ and $G_{2}$ be regular graphs of the same order and of the same degree. Let for $i=1,2, L\left(G_{i}\right)$ be the line graph of $G_{i}$ such that for any two adjacent vertices $u_{i}$ and $v_{i}$ of $L\left(G_{i}\right)$, there exists a third vertex $w_{i}$ in $L\left(G_{i}\right)$ which is not adjacent to either $u_{i}$ or $v_{i}$. Then $\overline{L\left(G_{1}\right)}$ and $\overline{L\left(G_{2}\right)}$ are $C D$-cospectral if and only if $G_{1}$ and $G_{2}$ are cospectral.

Proof. Follows from Eqs. (3), (4) and (5).

Lemma 4.3. Let $G_{1}$ and $G_{2}$ be connected, regular graphs of the same order $n>3$ and of the same degree. Let none of the three graphs $F_{1}, F_{2}$ and $F_{3}$ of Fig. 1 be an induced subgraph of $G_{i}, i=1,2$. Then $L\left(G_{1}\right)$ and $L\left(G_{2}\right)$ are $C D$-cospectral if and only if $G_{1}$ and $G_{2}$ are cospectral.

Proof. Follows from Eqs. (6) and (7).

Theorem 4.4. Let $G_{1}$ and $G_{2}$ be regular, non $C D$-cospectral graphs of the same order and of the same degree. Let for $i=1,2, L\left(G_{i}\right)$ be the line graph of $G_{i}$ such that for any two adjacent vertices $u_{i}$ and $v_{i}$ of $L\left(G_{i}\right)$, there exists a third vertex $w_{i}$ in $L\left(G_{i}\right)$ which is not adjacent to either $u_{i}$ or $v_{i}$. Then $\overline{L\left(G_{1}\right)}$ and $\overline{L\left(G_{2}\right)}$ form a pair of non $C D$-cospectral, $C D$-equienergetic graphs of equal order and of equal number of edges.

Proof. Follows from Lemma 4.1, Lemma 4.2 and Theorem 3.1. 
Theorem 4.5. Let $G_{1}$ and $G_{2}$ be connected, regular, non $C D$-cospectral graphs of the same order $n>3$ and of the same degree $r$. Let none of the three graphs $F_{1}$, $F_{2}$ and $F_{3}$ of Fig. 1 be an induced subgraph of $G_{i}, i=1,2$.

(i) If the smallest adjacency eigenvalue of $G_{i}, i=1,2$ is greater than or equal to $3-r$, then line graphs $L\left(G_{1}\right)$ and $L\left(G_{2}\right)$ form a pair of non $C D$-cospectral, $C D$ equienergetic graphs of equal order and of equal number of edges.

(ii) If the second largest adjacency eigenvalue of $G_{i}, i=1,2$ is smaller than $3-r$, then line graphs $L\left(G_{1}\right)$ and $L\left(G_{2}\right)$ form a pair of non $C D$-cospectral, $C D$ equienergetic graphs of equal order and of equal number of edges.

Proof. Follows from Lemma 4.1, Lemma 4.3 and Theorem 3.2.

Theorem 4.6. Let $G_{1}$ and $G_{2}$ be connected, non CD-cospectral, cubic, equienergetic graphs of the same order. Let none of the three graphs $F_{1}, F_{2}$ and $F_{3}$ of Fig. 1 be an induced subgraph of $G_{i}, i=1,2$. Then line graphs $L\left(G_{1}\right)$ and $L\left(G_{2}\right)$ form a pair of non $C D$-cospectral, $C D$-equienergetic graphs of equal order and of equal number of edges.

Proof. Follows from Lemma 4.1, Lemma 4.3 and Corollary 3.3.

Acknowledgement. The authors H. S. Ramane and K. C. Nandeesh are thankful to the University Grants Commission (UGC), Govt. of India for support through research grant under UPE FAR-II grant No. F 14-3/2012 (NS/PE).

\section{REFERENCES}

[1] Balakrishnan, R., "The energy of a graph", Linear Algebra Appl., 387 (2004), 287-295.

[2] Brankov, V., Stevanović, D. and Gutman, I., "Equienergetic chemical trees", J. Serb. Chem. Soc., 69 (2004), 549-553.

[3] Buckley, F. and Harary, F., Distance in Graphs, Addison-Wesley, Redwood, 1990.

[4] Cvetković, D., Rowlinson, P. and Simić, S., An Introduction to the Theory of Graph Spectra, Cambridge Univ. Press, Cambridge, 2010

[5] Gutman, I., "The energy of a graph", Ber. Math. Stat. Sekt. Forschungsz. Graz, 103 (1978), $1-22$.

[6] Harary, F., Graph Theory, Addison-Wesley, Reading, 1969.

[7] Ivanciuc, O., Ivanciuc, T. and Balaban, A.T., "The complementary distance matrix, a new molecular graph metric", ACH-Models Chem. 137(1) (2000), 57-82.

[8] Jenežić, D., Miličević, A., Nikolić, S. and Trinajstić, N., Graph Theoretical Matrices in Chemistry, Uni. Kragujevac, Kragujevac, 2007.

[9] Li, X., Shi, Y. and Gutman, I., Graph Energy, Springer, New York, 2012.

[10] Ramane, H.S., Gutman, I. and Ganagi, A.B., "On diameter of line graphs", Iranian J. Math. Sci. Inf., 8(1) (2013), 105-109.

[11] Ramane, H.S., Revankar, D.S., Gutman, I. and Walikar, H.B., "Distance spectra and distance energies of iterated line graphs of regular graphs", Publ. Inst. Math. (Beograd), 85 (2009), $39-46$.

[12] Ramane, H.S. and Walikar, H.B., "Construction of equienergetic graphs", MATCH Commun. Math. Comput. Chem., 57 (2007), 203-210. 
[13] Ramane, H.S., Walikar, H.B., Rao, S.B., Acharya, B.D., Hampiholi, P.R., Jog, S.R. and Gutman, I., "Equienergetic graphs", Kragujevac J. Math., 26 (2004), 5-13.

[14] Sachs, H., "Über selbstkomplementare Graphen", Publ. Math. Debrecen, 9 (1962), $270-288$.

[15] Sachs, H., "Über Teiler, Faktoren und charakteristische Polynome von Graphen, Teil II", Wiss. Z. TH Ilmenau, 13 (1967), 405-412.

[16] Senbagamalar, J., Baskar Babujee, J. and Gutman, I., "On Wiener index of graph complements", Trans. Comb., 3(2) (2014), 11-15.

[17] Xu, L. and Hou, Y., "Equienergetic bipartite graphs", MATCH Commun. Math. Comput. Chem., 57 (2007), 363-370. 
H. S. Ramane AND K. C. NANDEesh 